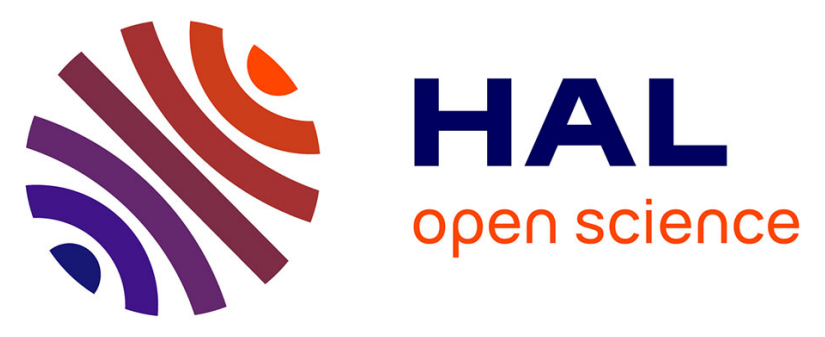

\title{
Dynapenia and sarcopenia in chronic haemodialysis patients: do muscle weakness and atrophy similarly influence poor outcome?
}

Jean-Sébastien Souweine, Grégoire Pasquier, Nils Kuster, Annie Rodriguez, Laure Patrier, Marion Morena, Eric Badia, F. Raynaud, Lotfi Chalabi, Nathalie Raynal, et al.

\section{To cite this version:}

Jean-Sébastien Souweine, Grégoire Pasquier, Nils Kuster, Annie Rodriguez, Laure Patrier, et al.. Dynapenia and sarcopenia in chronic haemodialysis patients: do muscle weakness and atrophy similarly influence poor outcome?. Nephrology Dialysis Transplantation, In press, 10.1093/ndt/gfaa353 . hal-03059820

\section{HAL Id: hal-03059820 https://hal.science/hal-03059820}

Submitted on 30 Jul 2021

HAL is a multi-disciplinary open access archive for the deposit and dissemination of scientific research documents, whether they are published or not. The documents may come from teaching and research institutions in France or abroad, or from public or private research centers.
L'archive ouverte pluridisciplinaire HAL, est destinée au dépôt et à la diffusion de documents scientifiques de niveau recherche, publiés ou non, émanant des établissements d'enseignement et de recherche français ou étrangers, des laboratoires publics ou privés. 


\section{Dynapaenia and sarcopaenia in chronic haemodialysis patients: do muscle weakness and atrophy similarly influence poor}

outcome?

Jean-Sébastien Souweine ${ }^{1,2, *}$, Grégoire Pasquier ${ }^{1, *}$, Nils Kuster ${ }^{1,2}$, Annie Rodriguez $^{3}$, Laure Patrier ${ }^{3}$, Marion Morena ${ }^{1,2}$, Eric Badia ${ }^{2}$, Fabrice Raynaud ${ }^{2}$, Lotfi Chalabi ${ }^{3}$, Nathalie Raynal ${ }^{3}$, Isabelle Ohresser ${ }^{3}$, Maurice Hayot ${ }^{2,4}$, Jacques Mercier ${ }^{2,4}$, Moglie Le Quintrec ${ }^{5}$, Fares Gouzi ${ }^{2,4}$ and Jean-Paul Cristol ${ }^{1,2}$

${ }^{1}$ Department of Biochemistry, University Hospital of Montpellier, University of Montpellier, Montpellier, France, ${ }^{2}$ PhyMedExp, University of Montpellier, INSERM, CNRS, Montpellier, France, ${ }^{3}$ AIDER, Montpellier, France, ${ }^{4}$ Department of Physiology, University Hospital of Montpellier, University of Montpellier, Montpellier, France and ${ }^{5}$ Department of Nephrology, University Hospital of Montpellier, University of Montpellier, Montpellier, France

${ }^{*}$ These authors contributed equally to this work.

${ }^{*}$ Clinical trial registration: NCT03845452

Correspondence to: Jean-Paul Cristol; E-mail: jp-cristol@chu-montpellier.fr

Prospective study

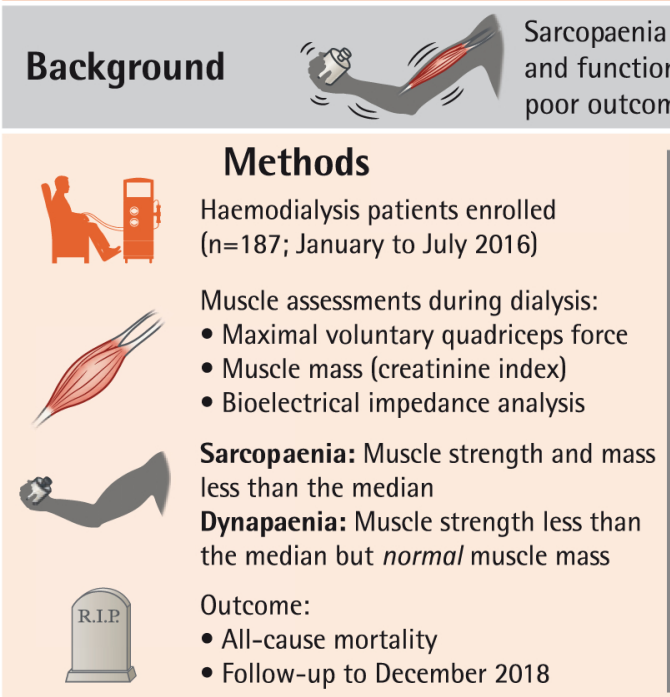

Dynapaenia and sarcopaenia in chronic haemodialysis patients: do muscle weakness and atrophy similarly influence poor outcome? 


\section{What is already known about this subject?}

- sarcopaenia defined as a decline in muscle mass and strength contributes to the frailty and emerges as an important risk factor of death in chronic haemodialysis (CHD) patients;

- dynapaenia, defined as a muscle weakness without a decrease in muscle mass, has been recently evidenced in CHD patients and confirms that muscle strength and muscle mass are not solely dependent on each other; and

- identification of dynapaenic in CHD patients may help defining a constitute disease phenotype as suggested in a recent cohort, and could partly explain why nutritional supplementation and rehabilitation had blunted effects in CHD patients. However, in CHD patients, the characteristics and clinical outcome of patients with dynapaenia remain unknown.

\section{What this study adds?}

- muscle function, assessed by muscle strength and physical activity, constitutes a better prognostic factor than muscle mass in CHD patients;

- dynapaenia was associated with a poor outcome after multivariate adjustment including age, whereas sarcopaenia did not remain statistically significant; and

- our findings highlighted the fundamental role of muscle function in comparison with muscle mass to predict mortality.

\section{What impact this may have on practice or policy?}

- first, our study highlights that screening for muscle dysfunction, such as weakness and physical inactivity and muscle mass assessment, is crucial to predict outcome of CHD patients. Indeed, assessing only muscle mass could blind the high risk of mortality associated with dynapaenia; and

- secondly, it suggests that identification of dynapaenia will help to propose a more targeted therapeutic intervention on muscle dysfunction and rehabilitation management with the eventual goal of improving dialysis patient outcomes as previously demonstrated in elderly patients. Finally, it can be hypothesized that muscle functional impairment is the consequence of structural abnormalities independently of muscle atrophy or ageing. Thus, muscle rehabilitation and physical exercise should be more suitable for patients with dynapaenia compared with a patient with sarcopaenia.

\section{ABSTRACT}

Background. Sarcopaenia, defined as a decline in both muscle mass and function, has been recognized as a major determinant of poor outcome in haemodialysis (HD) patients. It is generally assumed that sarcopaenia is driven by muscle atrophy related to protein-energy wasting. However, dynapaenia, defined as weakness without atrophy, has been characterized by a different disease phenotype from sarcopaenia. The aim of this study was to compare the characteristics and prognosis of sarcopaenic and dynapaenic patients among a prospective cohort of chronic HD (CHD) patients.

Methods. Two hundred and thirty-two CHD patients were enrolled from January to July 2016 and then followed prospectively until December 2018. At inclusion, weakness and atrophy were, respectively, evaluated by maximal voluntary force (MVF) and creatinine index (CI). Sarcopaenia was defined as the association of weakness and atrophy (MVF and CI below the median) while dynapaenia was defined as weakness not related to atrophy (MVF below the median, and CI above the median).

Results. From a total of 187 prevalent CHD patients [ $65 \%$ of men, age 65.3 (49.7-82.0) years], 44 died during the follow- up period of 23.7 (12.4-34.9) months. Sarcopaenia and dynapaenia were observed in 33.7 and $16 \%$ of the patients, respectively. Compared with patients with sarcopaenia, patients with dynapaenia were younger and with a lower Charlson score. In contrast, mortality rate was similar in both groups (38 and 27\%, respectively). After adjustment for age, sex, lean tissue index, serum albumin, highsensitivity C-reactive protein (hs-CRP), haemoglobin ( $\mathrm{Hb}$ ), normalized protein catabolic rate (nPCR), dialysis vintage and Charlson score, only patients with dynapaenia were at increased risk of death [hazard ratio $(\mathrm{HR})=2.99$, confidence interval 1.18-7.61; $\mathrm{P}=0.02$ ].

Conclusions. Screening for muscle functionality is highly warranted to identify patients with muscle functional impairment without muscle atrophy. In contrast to sarcopaenia, dynapaenia should appear as a phenotype induced by uraemic milieu, characterized by young patients with low Charlson score and poor prognosis outcome independently of serum albumin, hs$\mathrm{CRP}, \mathrm{Hb}, \mathrm{nPCR}$ and dialysis vintage.

Keywords: chronic haemodialysis, dynapaenia, muscle mass, muscle strength, sarcopaenia 
Sarcopaenia, defined as a decline in muscle mass and strength, is becoming a concerning challenge for chronic haemodialysis (CHD) patients $[1,2]$. Patients with sarcopaenia present decreased physiological reserves and poor response to stressors, the main features of frailty condition [3]. Thus, sarcopaenia contributes to frailty and emerges as an important risk factor of death [4].

While muscle mass and strength are physiologically interrelated in healthy subjects and CHD patients, basic physiological studies only showed a mild correlation between muscle strength and mass, and muscle strength should therefore not be considered as a surrogate for muscle mass in healthy subjects [5]. Dynapaenia, defined as a muscle weakness without decrease in muscle mass, has been recently evidenced in CHD patients and confirms that both entities are not solely dependent on each other in these patients $[6,7]$. Therefore, from a simple statistical point of view, a significant CHD patient cluster might experience muscle weakness without atrophy. In addition, the determinants of sarcopaenia do not impact muscle mass and strength similarly $[8,9]$. While muscle mass mainly depends on malnutrition and chronic inflammation related to proteinenergy wasting (PEW) [10-12], muscle strength has also been associated with other factors such as physical activity, neural activation and muscle contractile quality $[13,14]$.

Evidence of any distinction between dynapaenia and sarcopaenia in CHD patients should require different therapeutic strategies of muscle disorders such as those previously observed in elderly [7]. Thus, identification of dynapaenic CHD patients may help define a constitutive disease phenotype as suggested in a recent cohort [15], and could partly explain why nutritional supplementation and rehabilitation had blunted effects in CHD patients [16-19].

Yet, this muscle phenotype has never been identified, mainly because muscle strength remains poorly investigated in CHD patients. Only muscle mass is routinely investigated, either by bioelectrical impedance analysis (BIA) or by creatinine kinetic modelling [20-22]. However, weakness detection using a simple, inexpensive and reliable strain gauge could also be assessed in clinical practice [23]. Recently, it has been suggested that muscle strength per se was associated with poor clinical outcomes in CHD patients [24]. Defining a disease phenotype requires that patients of a same group share consistent clinical and physiological characteristic experiences and a consistent natural history (reflecting an underlying pathobiology and a predictable response to general and specific therapies) [25-27]. However, in CHD patients, the characteristics and clinical outcomes of patients with dynapaenia remain unknown. Indeed, it has never been demonstrated that such a group of dynapaenic CHD patients experiences a specific time course.

Therefore, the aim of this study was to compare the characteristics of sarcopaenic and dynapaenic patients among a prospective cohort of CHD patients. In addition, we aimed to test the association between muscle mass and function with mortality using readily applicable bedside tools, and the prognostic value of sarcopaenia and dynapaenia in a multivariate analysis.

\section{Study design and patients}

This is a post hoc cross-sectional analysis with prospective follow-up from an initial observational study investigating determinants of muscle weakness in prevalent CHD patients [6]. End-stage chronic renal disease patients, stable in HD for $>3$ months, were enrolled from January 2016 to July 2016 in HD units of Languedoc Roussillon, France (Lapeyronie University Hospital and centres issued from a non-profit dialysis association). Non-inclusion criteria were unstable comorbidities, acute illness for $<3$ months, cardiovascular contraindication to physical activity, and musculoskeletal or neurological disorders.

\section{Ethics statement}

The study was conducted according to the principles of the declaration of Helsinki and in compliance with International Conference on Harmonization/Good Clinical Practice regulations. The research protocol was initially approved by the local institutional ethics committee in January 2016 (with the following number: 2015-A01854-45) (ClinicalTrials.gov Identifier: NCT02806089) to investigate in a cross-sectional study the determinants of muscle weakness in prevalent CHD patients. A second approval has been further obtained in December 2018 (2018_IRB-MTP_12-02) (ClinicalTrials.gov Identifier: NCT03845452) to record mortality over a 2 -year period.

\section{Procedures}

Clinical examination, biological parameters, muscle mass and strength measurements were performed during the same dialysis session on the day of inclusion. Patient characteristics including age, gender, treatment modalities, duration of kidney disease and dialysis vintage were reviewed. History of comorbidities was performed using Charlson score for each patient. Evaluation of routine biological parameters including urea, creatinine, serum high-sensitivity C-reactive protein (hsCRP), serum albumin, bicarbonate and phosphates was carried out on an automated Cobas 8000 (Roche, Meylan, France). Dialysis adequacy was estimated by calculation of Daugirdas single pool $\left(s p K_{t} / V\right.$ urea). Normalized protein catabolic rate (nPCR) was calculated from pre- and post-dialysis blood urea and dialysis adequacy $[28,29]$. Patients were followed-up until December 2018 and mortality recorded. Follow-up time was censored at kidney transplantation, change of dialysis facility, lost to follow-up or end of study (December 2018).

\section{Muscular parameter determination}

Maximal voluntary force (MVF) of quadriceps and BIA were assessed during the same dialysis session.

Muscle mass was assessed by creatinine kinetic modelling using creatinine index (CI) and BIA using the body composition monitor (Fresenius Medical Care, Bad Homburg, Germany) $[21,30]$, with collection of lean tissue index (LTI) and fat tissue index (FTI). Muscle mass evaluation using BIA and CI was performed after the midweek HD session [21]. 
Voorrips score assessed physical activity and represented an integrative model of muscle function during the last 3 months before evaluation [31].

Assessment of quadriceps MVF was assessed using a hand-held dynamometer, as previously described [23].

\section{Sarcopaenia and dynapaenia diagnosis}

Sarcopaenia was defined as muscle strength and mass below the median of both MVF and CI. Dynapaenia was defined as the muscle strength below the median of MVF and a CI above the median value of $\mathrm{CI}$ (normal muscle mass).

\section{Statistical analyses}

Sample size was computed according to the method described in Latouche et al. [32] and implemented in the powerSurvEpi $\mathrm{R}$ package. In this context, sarcopaenia was considered as the bivariate covariate of interest. Assumptions needed for computation of sample size were based on the study of Isoyama et al. [15], as follows: prevalence of sarcopaenia in the study population $=21 \%$; observed hazard ratio $(\mathrm{HR})=2.94$; power $(1-\beta)$ $=80 \%$; proportion of death during follow-up $=29 \%$. This formula led to a sample size of 163 . Considering $10 \%$ of patients lost to follow-up, the needed sample size was 180 patients.

Population characteristics were expressed as mean (mean$-1 \mathrm{SD} /$ mean $+1 \mathrm{SD}$ ) for quantitative variables and as proportions for categorical variables. Logarithm transformations were performed for Voorrips score and hs-CRP data to obtain a normal sampling distribution. For quantitative data, multiple pairwise comparisons (Tukey test) were performed after a significant global test (ANOVA test if ANOVA hypotheses were fulfilled, Kruskal-Wallis test if not). For categorical data, multiple pairwise comparisons with Bonferroni correction were performed after a significant global chisquared test. Survival analysis was assessed using Cox proportional hazard model to test the association between muscle mass and function with mortality. All variables in univariate analysis were subsequently tested in multivariate analysis. A stepwise procedure using Akaike information criterion (AIC) was used to select potential variables in the final model. In addition, a Bayesian Information Criteria (BIC) was also tested (see Supplementary data, S1) [33].

The Kaplan-Meier method of survival was used to assess the ability of dynapaenia and sarcopaenia to predict all-cause mortality in the population. Except parameters used to define sarcopaenia or dynapaenia and Voorrips score, which is a redundant variable with MVF to assess muscle function, all variables in univariate analysis were subsequently tested in multivariate analysis. Cox regression analyses are presented as HRs with $95 \%$ confidence intervals using a stepwise procedure. A test was considered significant at $\mathrm{P}<0.05$. Analyses were carried out using the $\mathrm{R}$ version 3.5.1 software.

\section{RESULTS}

\section{Baseline characteristics of patients}

One hundred and eighty-seven CHD patients [65\% men, age $65.3(49.7-82.0)$ years] were included in the study (Figure 1). Charlson score was $5.8(3.6-8.1), s p K_{t} / V$ urea

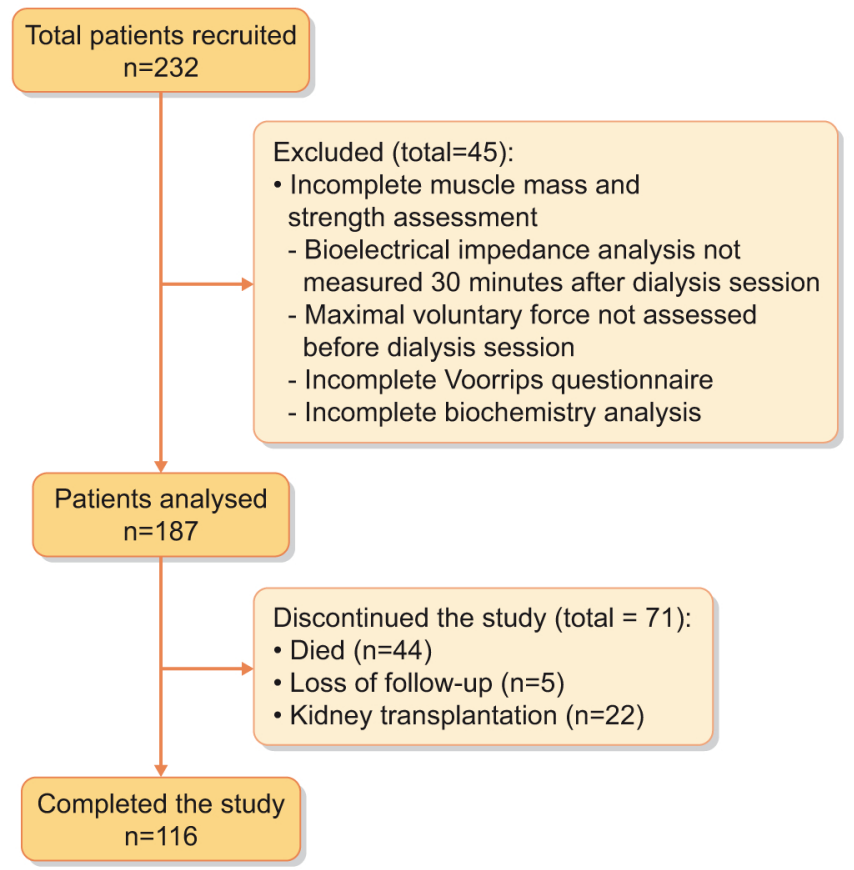

FIGURE 1: Flow chart diagram depicting number of patients evaluated for eligibility and number of patients included in analysis. 
was $1.8(1.4-2.1)$ and dialysis vintage was $5.6(0-12.4)$ years (Table 1). Muscle parameters were as follows: CI 19.1 (16.4-21.7) mg/kg/day, LTI 11.9 (9.3-14.5) kg/m², MVF 88.1 (48.5-127.8) Nm. A low physical activity, assessed by a Voorrips score at 6.9 (1.1-12.8) was observed (Table 1).

Causes of end-stage renal disease were glomerulonephritis (13.9\%), diabetes mellitus (15.5\%), hypertensive nephrosclerosis (14.4\%), intricate aetiology (diabetes and hypertension) (7.5\%), other cause (32\%) and undetermined nephropathy (16.0\%). There was no difference between patients with sarcopaenia, dynapaenia and patients with no dynapaenia-no sarcopaenia concerning aetiology of chronic kidney disease (CKD).

Sarcopaenia was present in $33.7 \%$ while dynapaenia was observed in $16.0 \%$ of the patients (Figure 2). Muscle mass, MVF and physical activity estimated by Voorrips score significantly increased in patients with no dynapaenia-no sarcopaenia ( $\mathrm{P}<0.05$ for all these comparisons). Body mass index (BMI), hs-CRP and haemoglobin ( $\mathrm{Hb}$ ) were not significantly different in patients with sarcopaenia, dynapaenia and no dynapaeniano sarcopaenia. Compared with sarcopaenic patients, patients with dynapaenia were younger and had few comorbidities $(\mathrm{P}<0.05)$. Finally, no significant difference in Voorrips score between dynapaenia and sarcopaenia groups was observed.

\section{Mortality}

Forty-four patients died within a mean follow-up period of 23.7 (16.8-34.3) months, $12(13 \%)$ in the no sarcopaenia-no dynapaenia group, 8 (27\%) in the dynapaenia group and 24 $(38 \%)$ in the sarcopaenia group. In the sarcopaenia group, mortality rate was more important compared with the no dynapaenia-no sarcopaenia group. Main causes of death were cardiovascular $(n=13 ; 30 \%)$, infection $(n=11 ; 25 \%)$, cancer $(n=7 ; 16 \%)$, other $(n=8 ; 18 \%)$ and unknown $(n=5 ; 11 \%)$. Concerning aetiology of death, no difference between all groups was found (Table 2).

\section{Muscle parameters and mortality rate}

Results from the Cox proportional hazard analyses exploring the predictive value for mortality of muscle parameters are reported in Table 3. Low CI, muscle strength and physical activity were risk factors for mortality in unadjusted analyses (respectively: $H R=0.79,95 \%$ confidence interval 0.69-0.9; $\mathrm{P}<0.001, \mathrm{HR}=0.98,95 \%$ confidence interval 0.97-0.99; $\mathrm{P}<0.0001, \mathrm{HR}=0.13,95 \%$ confidence interval $0.05-0.33$; $\mathrm{P}<0.001)$. Only a non-significant trend was observed with LTI in the univariate analysis $(\mathrm{HR}=0.89,95 \%$ confidence interval 0.79-1.00; $\mathrm{P}=0.057$ ).

In order to identify whether muscle mass, MVF or physical activity were independently associated with mortality, these parameters were introduced into a multivariate model using a stepwise procedure. MVF, Voorrips score and $\mathrm{Hb}$ but not $\mathrm{CI}$ remained statistically significant $(\mathrm{HR}=$ 0.99, 95\% confidence interval 0.98-1.00; $\mathrm{P}=0.015, \mathrm{HR}=$ $0.28,95 \%$ confidence interval $0.11-0.72 ; \mathrm{P}=0.008, \mathrm{HR}=$ $0.76,95 \%$ confidence interval 0.60-0.97; $\mathrm{P}=0.028$, respectively).

Table 1. Characteristics of the CKD patients according to presence or absence of muscle dysfunction

\begin{tabular}{|c|c|c|c|c|}
\hline Parameters & $\begin{array}{c}\text { Total population } \\
n=187\end{array}$ & $\begin{array}{l}\text { No dynapaenia-no sarcopaenia } \\
\qquad n=94\end{array}$ & $\begin{array}{c}\text { Dynapaenia } \\
n=30\end{array}$ & $\begin{array}{l}\text { Sarcopaenia } \\
\quad n=63\end{array}$ \\
\hline \multicolumn{5}{|c|}{ Demographic and clinical characteristics } \\
\hline Age, years & $65.3(49.7-82.0)$ & $62.1(45.6-78.6)^{\mathrm{s}}$ & $58.1(41.7-74.5)^{\mathrm{s}}$ & $74.8(64.1-85.5)^{\mathrm{n}, \mathrm{d}}$ \\
\hline Gender, men, $n(\%)$ & $122(65)$ & $77(82)^{\mathrm{s}}$ & $18(60)$ & $27(43)^{\mathrm{n}}$ \\
\hline$s p K_{t} / V$ & $1.8(1.4-2.1)$ & $1.6(1.3-2.0)^{\mathrm{s}}$ & $1.8(1.5-2.0)$ & $1.9(1.6-2.2)^{\mathrm{n}}$ \\
\hline Charlson score & $5.8(3.6-8.1)$ & $5.2(2.8-7.6)^{\mathrm{s}}$ & $5.2(3.3-7.1)^{\mathrm{s}}$ & $7.0(5.2-8.8)^{\mathrm{n}, \mathrm{d}}$ \\
\hline Duration of CKD, years & $13.6(2.1-25.2)$ & $13.8(2.6-25.1)$ & $16.4(1.7-31.1)$ & $12.1(1.9-22.3)$ \\
\hline Dialysis vintage, years & $5.6(0-12.4)$ & $5.3(0-11.7)$ & $8.3(0-18.0)$ & $4.9(0-10.3)$ \\
\hline $\mathrm{BMI}, \mathrm{kg} / \mathrm{m}^{2}$ & $24.8(20.0-29.7)$ & $25.0(21.2-28.8)$ & $24.5(19.2-29.7)$ & $24.7(18.7-30.6)$ \\
\hline Pre-dialysis systolic BP, $\mathrm{mmHg}$ & $132(107-158)$ & $138(113-162)^{\mathrm{s}}$ & $138(113-164)^{s}$ & $121(96-146)^{\mathrm{n}, \mathrm{d}}$ \\
\hline Pre-dialysis diastolic $\mathrm{BP}, \mathrm{mmHg}$ & $65(48-81)$ & $69(51-86)^{s}$ & $66(53-80)^{s}$ & $57(43-70)^{\mathrm{n}, \mathrm{d}}$ \\
\hline Voorrips score & $6.9(1.1-12.8)$ & $8.7(2.1-15.3)^{\mathrm{d}, \mathrm{s}}$ & $5.7(0-11.7)^{\mathrm{n}}$ & $4.9(1.3-8.4)^{\mathrm{n}}$ \\
\hline $\mathrm{MVF}, \mathrm{Nm}$ & $88.1(48.5-127.8)$ & $119.4(89.0-149.7)^{\mathrm{d}, \mathrm{s}}$ & $59.0(43.3-74.7)^{\mathrm{n}}$ & $55.4(40.0-70.8)^{\mathrm{n}}$ \\
\hline \multicolumn{5}{|l|}{ Impedancemetry parameters } \\
\hline FTI, $\mathrm{kg} / \mathrm{m}^{2}$ & $12.7(6.8-18.6)$ & $11.9(7.2-16.7)$ & $13.1(7.3-19.0)$ & $13.6(6.3-21.0)$ \\
\hline LTI, $\mathrm{kg} / \mathrm{m}^{2}$ & $11.9(9.3-14.5)$ & $13.0(10.6-15.4)^{\mathrm{d}, \mathrm{s}}$ & $11.4(9.3-13.5)^{\mathrm{n}, \mathrm{s}}$ & $10.5(8.2-12.8)^{\mathrm{n}, \mathrm{d}}$ \\
\hline SMMI, kg & $7.7(6.3-9.1)$ & $8.4(7.1-9.6)^{\mathrm{d}, \mathrm{s}}$ & $7.6(6.5-8.7)^{\mathrm{n}, \mathrm{s}}$ & $6.9(5.6-8.2)^{\mathrm{n}, \mathrm{d}}$ \\
\hline \multicolumn{5}{|l|}{ Laboratory parameters } \\
\hline $\mathrm{CI}, \mathrm{mg} / \mathrm{kg} /$ day & $19.1(16.4-21.7)$ & $20.2(17.6-22.8)^{\mathrm{s}}$ & $20.6(19.3-21.9)^{\mathrm{s}}$ & $16.8(15.4-18.3)^{\mathrm{n}, \mathrm{d}}$ \\
\hline Serum albumin, $g / \mathrm{L}$ & $38.0(33.5-42.5)$ & $38.9(34.3-43.6)^{\mathrm{s}}$ & $37.3(33.1-41.6)$ & $36.9(32.8-40.9)^{\mathrm{n}}$ \\
\hline hs-CRP, mg/L & $10.2(0-28.8)$ & $9.6(0-27.6)$ & $14.2(0-42.1)$ & $9.3(0-23.0)$ \\
\hline nPCR, g/kg/day & $0.91(0.68-1.14)$ & $0.93(0.70-1.15)$ & $0.97(0.72-1.23)$ & $0.86(0.64-1.08)$ \\
\hline Serum bicarbonate, $\mathrm{mmol} / \mathrm{L}$ & $22.5(19.9-25.2)$ & $22.5(19.9-25.0)$ & $21.6(19.4-23.8)^{\mathrm{s}}$ & $23.0(20.2-25.9)^{\mathrm{d}}$ \\
\hline Serum phosphate, $\mathrm{mmol} / \mathrm{L}$ & $1.44(0.93-1.96)$ & $1.51(0.97-2.05)^{\mathrm{s}}$ & $1.63(1.15-2.11)^{\mathrm{s}}$ & $1.26(0.82-1.7)^{\mathrm{n}, \mathrm{d}}$ \\
\hline $\mathrm{Hb}, \mathrm{g} / \mathrm{dL}$ & $11.1(9.7-12.5)$ & $11.1(9.6-12.5)$ & $11.4(10.1-12.7)$ & $11.1(9.7-12.4)$ \\
\hline
\end{tabular}

Results are expressed as mean (mean $-1 \mathrm{SD} ;$ mean $+1 \mathrm{SD}) . \mathrm{n}=$ significant difference with 'No dynapaenia-no sarcopaenia' group $(\mathrm{P}<0.05) . \mathrm{d}=$ significant difference with dynapaenia group $(\mathrm{P}<0.05) . \mathrm{s}=$ significant difference with sarcopaenia group $(\mathrm{P}<0.05)$.

SMMI, skeletal muscle mass index. 


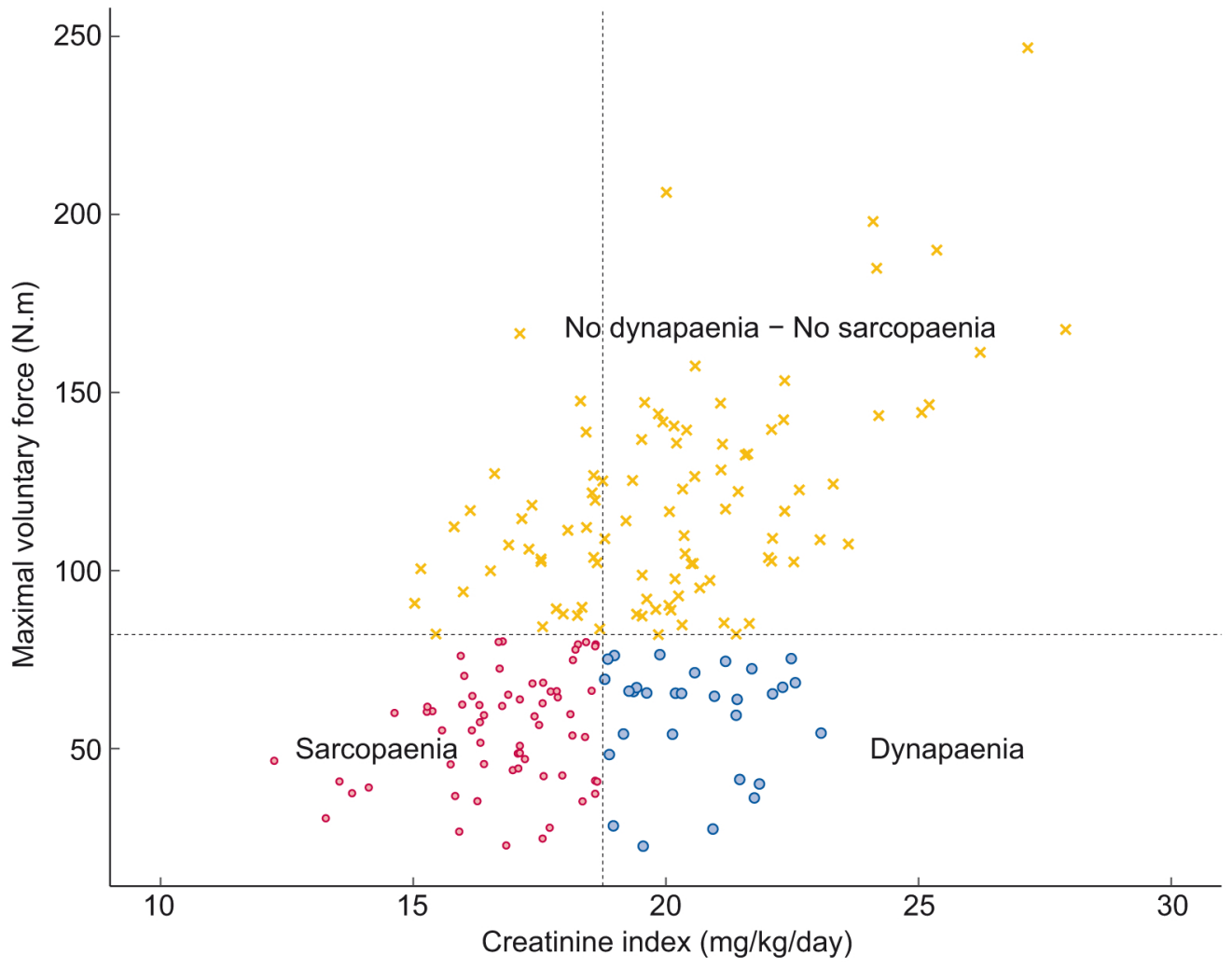

FIGURE 2: The distribution of CHD patients according to CI and MVF. Lines indicate the median of CI and MVF for the detection of sarcopaenia, dynapaenia and no dynapaenia-no sarcopaenia.

Table 2. Aetiology of death during the follow-up

\begin{tabular}{lccc} 
Characteristic & $\begin{array}{c}\text { Total population } \\
n=187\end{array}$ & $\begin{array}{c}\text { No dynapaenia-no sarcopaenia } \\
n=94\end{array}$ & $\begin{array}{c}\text { Dynapaenia } \\
n=30\end{array}$ \\
\hline Mortality, $n$ (\%) & $44(23)$ & $12(13)^{\mathrm{s}}$ & $8(27)$ \\
Main causes of death & 13 & & $24(38)^{\mathrm{n}}$ \\
Cardiovascular & 7 & 4 & 1 \\
Cancer & 11 & 4 & 2 \\
Infection & 8 & 1 & 2 \\
Others & 5 & 1 & 3 \\
Unknown & & 4 & 3 \\
\hline
\end{tabular}

$\mathrm{n}=$ significant difference with 'no dynapaenia-no sarcopaenia' group $(\mathrm{P}<0.0001) . \mathrm{s}=$ significant difference with sarcopaenia group $(\mathrm{P}<0.0001)$.

\section{Sarcopaenia/dynapaenia and mortality rate}

Kaplan-Meier method including sarcopaenia and dynapaenia versus no dynapaenia-no sarcopaenia is shown in Figure 3 and Cox proportional hazard models using dynapaenia or sarcopaenia are shown in Table 4.

Patients with no dynapaenia-no sarcopaenia were considered as the reference group. In the univariate analysis, Cox proportional hazard analyses showed that sarcopaenia was associated with a higher mortality risk $(\mathrm{P}=0.002)$ and dynapaenia tended to be significant $(\mathrm{P}=0.08)$. In order to identify whether sarcopaenia or dynapaenia were independently associated with mortality, all variables in the univariate analysis were subsequently introduced into a multivariate model using a stepwise procedure. In multivariate analysis, only dynapaenia but not sarcopaenia was associated with higher mortality risk $(\mathrm{HR}=2.99,95 \%$ confidence interval 1.18-7.61; $\mathrm{P}=0.02$,
$\mathrm{HR}=1.60,95 \%$ confidence interval $0.76-3.35 ; \mathrm{P}=0.21$, respectively).

\section{DISCUSSION}

The main finding of our work underlines that muscle strength and physical activity constitute a better prognostic factor than muscle mass in CHD patients. Indeed, dynapaenia was associated with a poor outcome after multivariate adjustment including age, whereas sarcopaenia did not remain statistically significant. Thus, weakness was associated with mortality independently of muscle mass and age in dynapaenia group, although the mean age difference was $\sim 20$ years between dynapaenic and sarcopaenic groups, suggesting an important role of muscle quality in CHD. 
Table 3. Cox proportional hazards analysis of factors predicting all-cause mortality

\begin{tabular}{|c|c|c|c|c|c|c|}
\hline \multirow[t]{2}{*}{ Parameters } & \multicolumn{3}{|c|}{ Unadjusted Cox proportional hazard } & \multicolumn{3}{|c|}{ Multivariate Cox proportional analysis } \\
\hline & HR & $95 \%$ confidence interval & $\mathrm{P}$-value & $\mathrm{HR}$ & $95 \%$ confidence interval & P-value \\
\hline Age, years & 1.05 & $(1.03-1.08)$ & $<0.001$ & 1.04 & $(1.01-1.06)$ & 0.011 \\
\hline $\begin{array}{l}\text { Gender (men } \\
\text { versus } \\
\text { women) }\end{array}$ & 0.75 & $(0.41-1.38)$ & 0.35 & - & - & - \\
\hline LTI, $\mathrm{kg} / \mathrm{m}^{2}$ & 0.89 & $(0.79-1.00)$ & 0.057 & - & - & - \\
\hline $\mathrm{CI}, \mathrm{mg} / \mathrm{kg} /$ day & 0.79 & $(0.69-0.9)$ & $<0.001$ & - & - & - \\
\hline $\mathrm{MVF}, \mathrm{Nm}$ & 0.98 & $(0.97-0.99)$ & $<0.001$ & 0.99 & $(0.98-1.00)$ & 0.015 \\
\hline Voorrips score & 0.13 & $(0.05-0.33)$ & $<0.001$ & 0.28 & $(0.11-0.72)$ & 0.008 \\
\hline $\begin{array}{l}\text { Serum albumin, } \\
\mathrm{g} / \mathrm{L}\end{array}$ & 0.88 & $(0.83-0.94)$ & $<0.001$ & - & - & - \\
\hline hs-CRP, mg/L & 1.16 & $(0.63-2.13)$ & 0.64 & - & - & - \\
\hline $\mathrm{Hb}, \mathrm{g} / \mathrm{dL}$ & 0.79 & $(0.63-0.99)$ & 0.04 & 0.76 & $(0.60-0.97)$ & 0.028 \\
\hline nPCR, g/kg/day & 0.23 & $(0.05-1.02)$ & 0.052 & - & - & - \\
\hline Charlson score & 1.32 & $(1.17-1.48)$ & $<0.001$ & - & - & - \\
\hline $\begin{array}{l}\text { Dialysis vintage, } \\
\text { years }\end{array}$ & 1.00 & $(0.95-1.04)$ & 0.9 & - & - & - \\
\hline$s p K_{t} / V$ & 0.77 & $(0.31-1.9)$ & 0.57 & 0.42 & $(0.18-0.99)$ & 0.048 \\
\hline
\end{tabular}

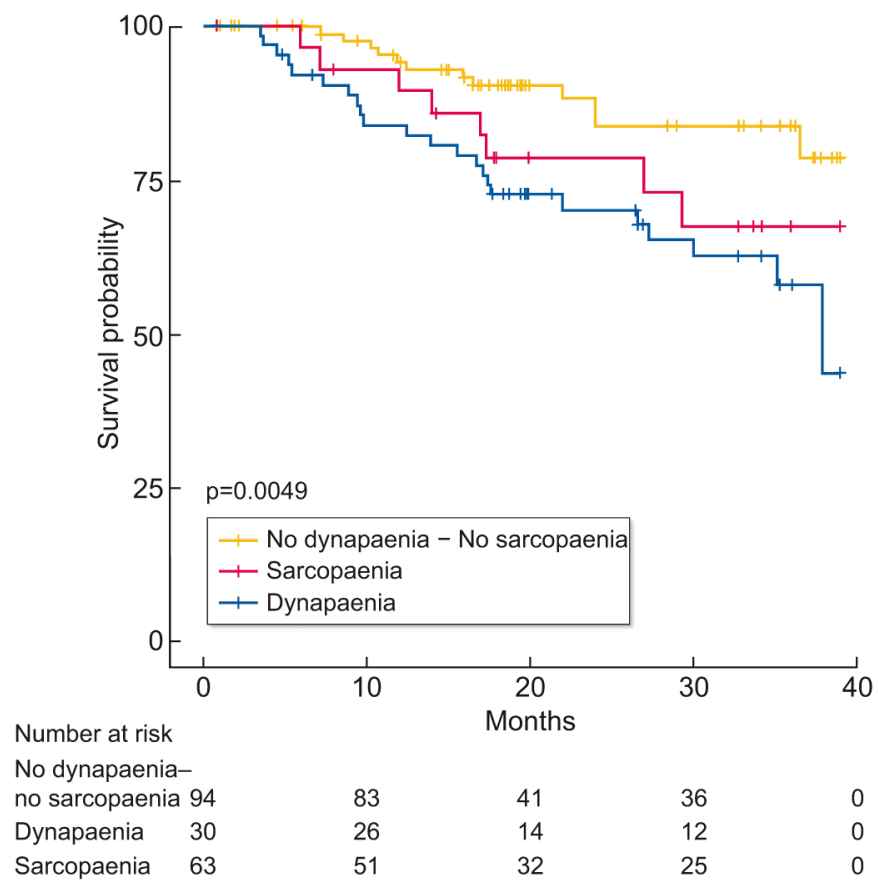

FIGURE 3: Kaplan-Meier curve for survival free from no dynapaenia-no sarcopaenia, dynapaenia and sarcopaenia among CHD patients.

\section{Exploring muscle function beyond muscle mass}

Muscle mass is recognized as an important predictor of mortality in CHD patients $[21,22,30]$. In the dialysis population, muscle mass could be assessed by different methods including DEXA, impedancemetry or creatinine kinetic modelling. DEXA is recognized as the gold standard to evaluate body composition and muscle mass, but because it is costly, timeconsuming and not a portable technique it is not appropriate for daily practice. Thus, it has been recommended to use BIA at the bedside, which is a simple, non-invasive and inexpensive method well correlated with DEXA measurements [20]. CI, influenced by low protein dietary intake, was performed on the midweek HD session as recommended by experts [30]. Interestingly, we confirmed in our study the negative correlation between $\mathrm{CI}$ and mortality in the univariate analysis. In addition, the CI threshold value for mortality was at $18.8 \mathrm{mg} / \mathrm{kg} /$ day, which is close to the one published in previous studies $(18.9 \mathrm{mg} / \mathrm{kg} /$ day $)[21,22,30]$. However, this association between muscle mass and mortality does not reach significance in the multivariate analysis (Table 3). This unexpected result may be explained by the strong association between muscle function (Voorrips score and MVF) and mortality in the multivariate analysis, highlighting the importance of a global screening of muscle function with specific values in $\mathrm{HD}$ population. 
Table 4. Risk factors of mortality in unadjusted and adjusted after AIC stepwise analysis including dynapaenia and sarcopaenia groups

No dynapaenia-no sarcopaenia

Dynapaenia

Sarcopaenia

Age, years

Gender (men versus women)

LTI, $\mathrm{kg} / \mathrm{m}^{2}$

Serum albumin, $g / \mathrm{L}$

hs-CRP, mg/L

$\mathrm{Hb}, \mathrm{g} / \mathrm{dL}$

nPCR, $\mathrm{g} / \mathrm{kg} /$ day

Charlson score

Dialysis vintage, years

$s p K_{t} / V$

\section{Reference}

$2.2(0.9-5.4)$

$3.0(1.5-6.0)$

$1.05(1.03-1.08)$

$0.75(0.41-1.38)$

$0.89(0.79-1.00)$

$0.88(0.83-0.94)$

$1.16(0.63-2.13)$

$0.79(0.63-0.99)$

$0.23(0.05-1.02)$

$1.32(1.17-1.48)$

$1.00(0.95-1.04)$

$0.77(0.31-1.9)$
Reference

$2.99(1.18-7.61) \quad \mathbf{0 . 0 2}$

$1.60(0.76-3.35)$

$1.03(0.99-1.07)$

0.21

0.13

0.35

0.057

$<0.001$

0.64

0.04

0.052

$<0.001$

0.9

0.57
$-$

$-$

$0.93(0.87-1.05)$

0.086

$-$

$0.82(0.63-1.05)$

0.11

$-$

$1.21(1.00-1.46)$

0.049
In CHD patients, no a priori specific and validated cut-off value exists to identify muscle mass and strength diminution. Reference values are speculated using reference values from older patients without CKD or low muscle mass and strength of $\mathrm{CHD}$ patients are defined against young reference populations $[1,15,24]$. This methodology leads to results that are sometimes difficult to interpret. Nevertheless, assessment of MVF of quadriceps, using a handheld dynamometer, has been recently validated against the gold standard (dynamometer chair) [23]. This reliable tool presents many advantages: (i) it can be used at the bedside and (ii) a handheld dynamometer limits measurement biases, compared with handgrip, because it is not influenced by local disorders such as arteriovenous fistula $[1,23,24]$. Voorrips score also assesses muscle function using an integrative model of physical activity in the last 3 months before muscular evaluations [34]. Interestingly, muscle strength and physical activity are closely linked $(r=039, \mathrm{P}<0.001)$. Although our results demonstrate the importance of physical activity and muscle strength, we could not currently affirm the implication of the unloading and deconditioning in muscle abnormalities of $\mathrm{CHD}$ patients.

Outcome is mainly driven by uraemia-induced muscle dysfunction and dynapaenia

Table 3 demonstrates in multivariate analysis that muscle function assessed by muscle strength and physical activity, but not muscle mass, is associated with poor outcome. This result is in agreement with previous reports in the general population or in HD [15, 24, 35]. Indeed, in incident [15] and prevalent [24] dialysis patients, low muscle strength was more strongly associated with mortality than low muscle mass.

The key role of muscle function and muscle strength is further enhanced by the relationship between dynapaenia and mortality. Indeed, dynapaenia was associated with a poor outcome after multivariate adjustment including age, sex, LTI, serum albumin, hs-CRP, serum bicarbonates, dialysis vintage and Charlson score, whereas sarcopaenia did not remain statistically significant (Table 4).

In the general population, dynapaenia is related to agerelated decline in muscle strength [36], and muscle strength decline is greater in men than women. In contrast to the first studies in CHD patients showing similarities with age-related sarcopaenia $[18,37,38]$ (fibre atrophy, activation of ubiquitinproteasome catabolic pathway, etc.), older age was not a significant determinant of poor prognosis in multivariate analysis. This result is in line with recent studies showing that muscle remodelling in CHD patients and its underlying proteome is disease-specific [39] and not an accelerated ageing process. In particular, the fibre transition from slow-to-fast type reported in CHD patients [39-43] was the opposite of what is basically observed in ageing [44]. In addition, muscle atrophy is a relatively small contributor to the loss of muscle strength in older people especially in CHD patients $[6,45,46]$. As previously reported [15], gender was not associated with prognosis in multivariate analysis despite a different sex ratio between groups. Thus in CKD, behind the age-related decline in muscle mass, muscle function alteration was driven by many other factors such as uraemic toxins [47].

Thus, weakness was associated with mortality independently of muscle mass and age in dynapaenia group. This result highlights the role of muscle quality in CHD outcome and suggested that dynapaenia could appear as a muscular phenotype in CHD patients.

\section{Is dynapaenia a muscular phenotype in CHD patients?}

Dynapaenic and sarcopaenic CHD patients presented different clinical and biological characteristics (Table 1). Since dynapaenic patients were younger with few comorbidities, it could 
be hypothesized that dynapaenic patients are pre-sarcopaenic patients and that these two groups correspond to the same patients taken at a different time point of the disease course. Indeed, an experimental study has demonstrated that muscle weakness appeared at an earlier stage of renal failure than muscle atrophy [48]. However, two results argue against this hypothesis of an historical continuum from one cluster to another. First, younger dynapaenic CHD patients were characterized by worse acidosis, phosphate levels and blood pressure (BP), which are classical indicators of CKD severity, than older sarcopaenic patients (Table 1). Classically, acidosis was strongly correlated with decreased kidney function [49] and could stimulate myostatin and muscle atrophy [50]. Serum bicarbonates are significantly increased in the sarcopaenic group in comparison with dynapaenic group, but not with the no sarcopaenicno dynapaenic group. In CHD, nutrition and low protein intake should be taken into account in the interpretation of serum bicarbonates $[51,52]$. Interestingly, albumin decreased in sarcopaenic patients but not in dynapaenic ones, suggesting a role of nutrition in age-related decline in muscle strength in sarcopaenic group.

The relationship between serum phosphates and muscle function remains a question of debate and could be modified by nutritional factors, bone and mineral disorders, inflammation, etc. Chen et al. first suggested that phosphate level was associated with low muscle strength [53]. In agreement with the recent report of MONDO (MONitoring Dialysis Outcome initiative), we observed a weak positive correlation between serum phosphate and MVF $(r=0.19, \mathrm{P}=0.016)$ [54]. Secondly, younger dynapaenic CHD patients did not have a better prognosis than older and comorbid sarcopaenic patients (Table 2). Thus, dynapaenic patients had a specific time course of the disease independently of age or comorbidities.

Given the accepted definition of a disease phenotype, patients with dynapaenia or sarcopaenia could constitute different phenotypes $[25,26]$. When comparing our patient groups, they shared specific clinical characteristics, natural history and specific prognosis (Tables 1 and 2) As reported in Table 2, the mortality rate increased from the no dynapaenia-no sarcopaenia group (13\%) to the dynapaenia group (27\%) and the sarcopaenia group (38\%). Although not statistically different, more deaths seemed to occur in sarcopaenic patients who were older than dynapaenic ones. More events were also registered in dynapaenic patients in comparison with the no sarcopaenia-no dynapaenia group, despite a similar mean age. We can hypothesize that in older sarcopaenic patients, death was probably strongly driven by age and comorbidities, whereas muscular quality was a determinant in younger HD patients. Because different prognosis factors have been previously identified in large CHD patients cohorts, the possibility of phenotypes in CHD patients has been proposed [40, 41]. Yet, our study is the first one to show that a dynapaenic phenotype in $\mathrm{HD}$ is associated with a high mortality rate despite young age, low Charlson score and metabolic acidosis, and a maintained systolic BP.

The link between disease phenotype and muscle functional impairment has not been currently characterized. Muscle biopsy studies in CHD patients have shown (i) a switch in the muscular fibre phenotype from Types I to II $[42,55,56]$, (ii) a fibre atrophy [57] and (iii) a mitochondrial dysfunction [58]. Thus, sarcopaenic CHD patients may experience a fibre atrophy while dynapaenic patients may rather experience an oxidative switch $[39,58,59]$. In addition, specific mechanisms could specifically lead to muscle weakness without atrophy, like architecture and neuromuscular transmission [60, 61]. The relative contribution of age, uraemic milieu and PEW in these phenotypes remains to be investigated. Altogether, future cellular muscle studies should characterize the phenotype (i.e. dynapaenic or sarcopaenic) of CHD patients.

\section{Clinical relevance}

This study has important implications for clinical practice and future research. First, it highlights that screening for muscle dysfunction, such as weakness, physical inactivity and muscle mass assessment, is crucial to predict outcome of CHD patients. Indeed, assessing only muscle mass with creatinine modelling or BIA could blind the high risk of mortality associated with dynapaenia. Secondly, it suggests that the identification of dynapaenia will help to propose a more targeted therapeutic intervention on muscle dysfunction and rehabilitation management with the eventual goal of improving dialysis patient outcomes, as previously demonstrated in elderly patients [7]. Finally, it can be hypothesized that muscle functional impairment is the consequence of structural abnormalities independently of muscle atrophy or ageing. Thus, muscle rehabilitation and physical exercise should be more suitable for patients with dynapaenia compared with patients with sarcopaenia.

\section{Study limitations}

This study had some limitations. The sample size was relatively low in this monocentric study. Model selection of variables associated with outcome remains crucial [33]. Some authors recommended BIC as a pertinent statistical method for model selection. Since BIC penalizes complex models, with a high number of parameters, it could be concluded that, besides a potential masking effect of comorbidities and albumin, dynapaenia weighted more than sarcopaenia in both AIC and BIC models. Nonetheless, our main objective, which was to compare the characteristics and outcomes of dynapaenic or sarcopaenic patients, has been achieved. In addition, the stability of these phenotypes should be confirmed in other CHD populations. However, these results may encourage future studies to evaluate structural muscle abnormalities and their causal effects in functional impairment leading to different muscle phenotypes in CHD patients.

\section{CONCLUSION}

In conclusion, screening for muscle functionality is highly warranted to identify patients with muscle functional impairment without muscle atrophy. Dynapaenia might appear as a phenotype induced by uraemic milieu, characterized by young patients with few comorbidities and poor prognosis outcome independently of other adjustment factors. Conversely, sarcopaenia should be mainly associated with ageing and comorbidities in CHD patients. Thus, the research focus should 
be to improve muscle function and to investigate the impact of rehabilitation strategy upon the different phenotypes of CHD patients according to their distinctive muscle characteristics.

\section{ACKNOWLEDGEMENTS}

The authors acknowledge the Montpellier University Hospital for supporting the study. All authors declare that the submitted work has not been published before (either in English or in any other language) and that the work is not under consideration for publication elsewhere.

\section{FUNDING}

J.-S.S. was supported by a grant from the French Society of Nephrology.

\section{AUTHORS' CONTRIBUTIONS}

Conceptualization by J.-S.S., M.H., F.G. and J.-P.C. Data curation was done by A.R. Formal analysis was done G.P. and N.K. Funding acquisition by J.-S.S. and J.-P.C. Investigation and methodology by J.-S.S., G.P., E.B. and F.R. Project administration was carried out by J.-P.C. Resources by L.C., L.P., N.R., I.O. and M.L.Q. Software by G.P., A.R. and N.K. Supervision, validation and visualization were done by E.B., F.R., M.H., M.L.Q., F.G. and J.-P.C. Writing the original draft, and review and editing were by J.-S.S., M.M., M.L.Q., J.M., M.H., F.G. and J.-P.C.

\section{CONFLICT OF INTEREST STATEMENT}

All authors declare that they have no conflict of interest.

\section{REFERENCES}

1. Cruz-Jentoft AJ, Bahat G, Bauer J et al. Sarcopenia: revised European consensus on definition and diagnosis. Age Ageing 2019; 48: 16-31

2. Kittiskulnam P, Carrero JJ, Chertow GM et al. Sarcopenia among patients receiving hemodialysis: weighing the evidence. J Cachexia Sarcopeni Muscle 2017; 8: 57-68

3. von Haehling S, Morley JE, Anker SD. An overview of sarcopenia: facts and numbers on prevalence and clinical impact. J Cachexia Sarcopenia Muscle 2010; 1: 129-133

4. Pereira RA, Cordeiro AC, Avesani CM et al. Sarcopenia in chronic kidney disease on conservative therapy: prevalence and association with mortality. Nephrol Dial Transplant 2015; 30: 1718-1725

5. Clark BC, Manini TM. Sarcopenia =/= dynapenia. J Gerontol 2008; 63: 829-834

6. Souweine JS, Kuster N, Chenine L et al. Physical inactivity and protein energy wasting play independent roles in muscle weakness in maintenance haemodialysis patients. PLoS One 2018; 13: e0200061

7. Clark BC, Manini TM. What is dynapenia? Nutrition 2012; 28: 495-503

8. Stenvinkel P, Carrero JJ, von Walden F et al. Muscle wasting in end-stage renal disease promulgates premature death: established, emerging and potential novel treatment strategies. Nephrol Dial Transplant 2016; 31: 1070-1077

9. Bataille S, Serveaux M, Carreno E et al. The diagnosis of sarcopenia is mainly driven by muscle mass in hemodialysis patients. Clin Nutr 2017; 36: $1654-1660$
10. Fouque D, Kalantar-Zadeh K, Kopple J et al. A proposed nomenclature and diagnostic criteria for protein-energy wasting in acute and chronic kidney disease. Kidney Int 2008; 73: 391-398

11. Carrero JJ, Stenvinkel P, Cuppari L et al. Etiology of the protein-energy wasting syndrome in chronic kidney disease: a consensus statement from the International Society of Renal Nutrition and Metabolism (ISRNM). $J$ Renal Nutr 2013; 23: 77-90

12. Koppe L, Fouque D, Kalantar-Zadeh K. Kidney cachexia or protein-energy wasting in chronic kidney disease: facts and numbers. J Cachexia Sarcopenia Muscle 2019; 10: 479-484

13. Kim JK, Choi SR, Choi MJ et al. Prevalence of and factors associated with sarcopenia in elderly patients with end-stage renal disease. Clin Nutr 2014; 33: 64-68

14. Wang XH, Mitch WE. Mechanisms of muscle wasting in chronic kidney disease. Nat Rev Nephrol 2014; 10: 504-516

15. Isoyama N, Qureshi AR, Avesani CM et al. Comparative associations of muscle mass and muscle strength with mortality in dialysis patients. Clin J Am Soc Nephrol 2014; 9: 1720-1728

16. Chowdhury R, Peel NM, Krosch $M$ et al. Frailty and chronic kidney disease: a systematic review. Arch Gerontol Geriatr 2017; 68: 135-142

17. Heiwe S, Jacobson SH. Exercise training in adults with CKD: a systematic review and meta-analysis. Am J Kidney Dis 2014; 64: 383-393

18. Stenvinkel P, Ekström TJ. Epigenetics and the uremic phenotype: a matter of balance. Contrib Nephrol 2008; 161: 55-62

19. Carrero JJ, Stenvinkel P. The vulnerable man: impact of testosterone deficiency on the uraemic phenotype. Nephrol Dial Transplant 2012; 27: 4030-4041

20. Carrero JJ, Johansen KL, Lindholm B et al. Screening for muscle wasting and dysfunction in patients with chronic kidney disease. Kidney Int 2016; 90: 53-66

21. Marcelli D, Usvyat LA, Kotanko $\mathrm{P}$ et al. Body composition and survival in dialysis patients: results from an international cohort study. Clin J Am Soc Nephrol 2015; 10: 1192-1200

22. Terrier N, Jaussent I, Dupuy AM et al. Creatinine index and transthyretin as additive predictors of mortality in haemodialysis patients. Nephrol Dial Transplant 2007; 23: 345-353

23. Souweine JS, Boudet A, Chenine L et al. Standardized method to measure muscle force at the bedside in hemodialysis patients. J Renal Nutr 2017; 27: 194-200

24. Kittiskulnam P, Chertow GM, Carrero JJ et al. Sarcopenia and its individual criteria are associated, in part, with mortality among patients on hemodialysis. Kidney Int 2017; 92: 238-247

25. Han MK, Agusti A, Calverley PM et al. Chronic obstructive pulmonary disease phenotypes: the future of COPD. Am J Respir Crit Care Med 2010; 182: 598-604

26. Wenzel SE. Asthma phenotypes: the evolution from clinical to molecular approaches. Nat Med 2012; 18: 716-725

27. Cooper DN, Krawczak M, Polychronakos C et al. Where genotype is not predictive of phenotype: towards an understanding of the molecular basis of reduced penetrance in human inherited disease. Hum Genet 2013; 132: 1077-1130

28. Garred LJ, Barichello DL, Canaud BC et al. Simple equations for protein catabolic rate determination from pre dialysis and post dialysis blood urea nitrogen. ASAIO J 1995; 41: 889-895

29. Daugirdas JT. Second generation logarithmic estimates of single-pool variable volume Kt/V: an analysis of error. J Am Soc Nephrol 1993; 4: 1205-1213

30. Canaud B, Granger Vallée A, Molinari N et al. Creatinine index as a surrogate of lean body mass derived from urea $\mathrm{Kt} / \mathrm{V}$, pre-dialysis serum levels and anthropometric characteristics of haemodialysis patients. PLoS One 2014; 9: e93286

31. Anderton N, Giri A, Wei G et al. Sedentary behavior in individuals with diabetic chronic kidney disease and maintenance hemodialysis. J Renal Nutr 2015; 25: 364-370

32. Latouche A, Porcher R, Chevret S. Sample size formula for proportional hazards modelling of competing risks. Statist Med 2004; 23: 3263-3274

33. Kuha J. AIC and BIC: comparisons of assumptions and performance. Sociol Methods Res 2004; 33: 188-229 
34. Voorrips LE, Ravelli AC, Dongelmans PC et al. A physical activity questionnaire for the elderly. Med Sci Sports Exerc 1991; 23: 974-979

35. Mitchell WK, Williams J, Atherton $P$ et al. Sarcopenia, dynapenia, and the impact of advancing age on human skeletal muscle size and strength; a quantitative review. Front Physiol 2012; 3: 260

36. Ling CHY, Gussekloo J, Trompet S et al. Clinical determinants of low handgrip strength and its decline in the oldest old: the Leiden 85-plus Study. Aging Clin Exp Res 2020

37. Panaye M, Kolko-Labadens A, Lasseur C et al. Phenotypes influencing low physical activity in maintenance dialysis. J Renal Nutr 2015; 25: 31-39

38. Musso CG, Jauregui JR, Macías Núñez JF. Frailty phenotype and chronic kidney disease: a review of the literature. Int Urol Nephrol 2015; 47: 1801-1807

39. Aniort J, Stella A, Philipponnet C et al. Muscle wasting in patients with endstage renal disease or early-stage lung cancer: common mechanisms at work. J Cachexia Sarcopenia Muscle 2019; 10: 323-337

40. Smyth LJ, Duffy S, Maxwell AP et al. Genetic and epigenetic factors influencing chronic kidney disease. Am J Physiol Renal Physiol 2014; 307: F757-F776

41. Webster AC, Nagler EV, Morton RL et al. Chronic kidney disease. Lancet 2017; 389: 1238-1252

42. Johansen KL, Shubert T, Doyle J et al. Muscle atrophy in patients receiving hemodialysis: effects on muscle strength, muscle quality, and physical function. Kidney Int 2003; 63: 291-297

43. Lee SW, Dai G, Hu Z et al. Regulation of muscle protein degradation: coordinated control of apoptotic and ubiquitin-proteasome systems by phosphatidylinositol 3 kinase. J Am Soc Nephrol 2004; 15: 1537-1545

44. Gouzi F, Maury J, Molinari N et al. Reference values for vastus lateralis fiber size and type in healthy subjects over 40 years old: a systematic review and metaanalysis. J Appl Physiol (1985) 2013; 115: 346-354

45. Clark BC, Fernhall B, Ploutz-Snyder LL. Adaptations in human neuromuscular function following prolonged unweighting: I. Skeletal muscle contractile properties and applied ischemia efficacy. J Appl Physiol (1985) 2006; 101: $256-263$

46. Delmonico MJ, Harris TB, Visser M et al.; Health AgingBody Composition Study. Longitudinal study of muscle strength, quality, and adipose tissue infiltration. Am J Clin Nutr 2009; 90: 1579-1585

47. Enoki $Y$, Watanabe $H$, Arake R et al. Indoxyl sulfate potentiates skeletal muscle atrophy by inducing the oxidative stress-mediated expression of myostatin and atrogin-1. Sci Rep 2016; 6: 32084

48. Tamaki M, Miyashita K, Wakino $\mathrm{S}$ et al. Chronic kidney disease reduces muscle mitochondria and exercise endurance and its exacerbation by
2014; 85: 1330-1339

49. Kraut JA, Madias NE. Metabolic acidosis of CKD: an update. Am J Kidney Dis 2016; 67: 307-317

50. Stanislas B, Philippe C, Denis F et al. Myostatin and muscle atrophy during chronic kidney disease. Nephrol Dial Transplant 2020; doi: 10.1093/ndt/gfaa129 (online ahead of print)

51. Wu DY, Shinaberger CS, Regidor DL et al. Association between serum bicarbonate and death in hemodialysis patients: is it better to be acidotic or alkalotic? Clin J Am Soc Nephrol 2006; 1: 70-78

52. Chauveau P, Rigothier C, Combe C. Con: higher serum bicarbonate in dialysis patients is protective. Nephrol Dial Transplant 2016; 31: 1226-1229

53. Chen, YY Kao TW, Chou CW et al. Exploring the link between serum phosphate levels and low muscle strength, dynapenia, and sarcopenia. Sci Rep 2018; 8: 3573

54. Canaud B, Ye X, Usvyat L et al. Clinical and predictive value of simplified creatinine index used as muscle mass surrogate in end-stage kidney disease haemodialysis patients-results from the international MONitoring Dialysis Outcome initiative. Nephrol Dial Transplant 2020; 35: 2161-2171

55. Ahonen RE, Mäkitie J, Kock B. Striated muscle capillaries in uremic patients and in renal transplant recipients. Arch Intern Med 1981; 141: 867-869

56. Shah AJ, Sahgal V, Quintanilla AP et al. Muscle in chronic uremia-a histochemical and morphometric study of human quadriceps muscle biopsies. Clin Neuropathol 1983; 2: 83-89

57. Lewis MI, Fournier M, Wang $\mathrm{H}$ et al. Metabolic and morphometric profile of muscle fibers in chronic hemodialysis patients. J Appl Physiol 2012; 112: 72-78

58. Gamboa JL, Billings FT, Bojanowski MT et al. Mitochondrial dysfunction and oxidative stress in patients with chronic kidney disease. Physiol Rep 2016; 4: e12780

59. Zhang YY, Gu LJ, Huang J et al. CKD autophagy activation and skeletal muscle atrophy-a preliminary study of mitophagy and inflammation. Eur $J$ Clin Nutr 2019; 73: 950-960

60. Clark BC, Taylor JL. Age-related changes in motor cortical properties and voluntary activation of skeletal muscle. Curr Aging Sci 2011; 4: 192-199

61. McGregor RA, Cameron-Smith D, Poppitt SD. It is not just muscle mass: a review of muscle quality, composition and metabolism during ageing as determinants of muscle function and mobility in later life. Longev Healthspan 2014; 3: 9 